Variation in lower leg growth with alternate day steroid treatment 983

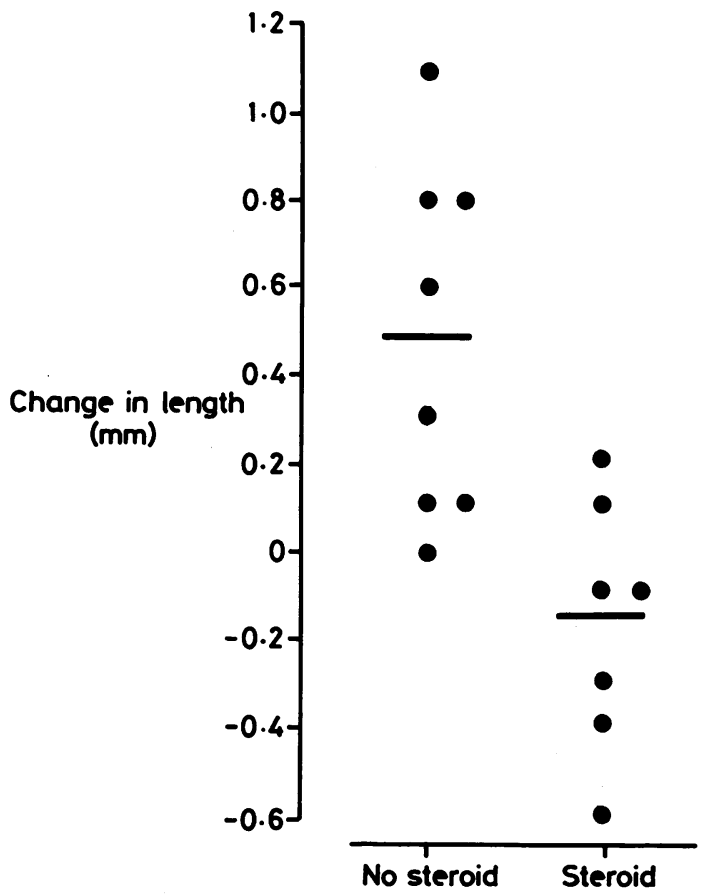

Fig 2 Variation in lower leg growth with alternate day steroid treatment.

\section{Discussion}

The knemometer provides a valuable means of observing biological phenomena related to short term, and ultra short term growth changes of the lower leg. The magnitude of the observed fluctuations in lower leg length in this case are well within the observed capabilities of the apparatus. ${ }^{2}$ The mechanism of the growth inhibition due to steroid administration is uncertain but is probably secondary to a peripheral blocking of the action of growth hormone. ${ }^{6}$ We postulate that the observed loss of length on days when steroids were administered is due to postural compression of non-growing cartilage and bone and is similar to the loss of length seen during illness or catabolic stress that we have previously described. ${ }^{2}$ The observed differences in lower leg length probably do represent true changes in bone length rather than a soft tissue effect and could represent the first direct observation of the growth sparing effect of alternate day steroid regimes.

We thank Mrs M Pickering for performing the auxological observations.

\section{References \\ 1 Valk IM, Langhout Chabloz AME, Smals AGH, Kloppenborg PWC, Cassorla FG, Schutte EAST. Accurate measurements of the lower leg length and the ulnar length and its application in short term growth measurement. Growth 1983;47:53-66. \\ 2 Wales JKH, Milner RDG. Knemometry in assessment of linear growth. Arch Dis Child 1987;62:166-71. \\ 3 Valk IM, Langhout Chabloz AME, Van Gilst W. Intradaily variation of the human lower leg length and short term growth-a longitudinal study of 14 children. Growth 1983;47:397-402. \\ ${ }^{4}$ Hermanussen M, Sippell WG, Valk IM. Knemometric monitor- ing of early effects of human growth hormone on leg length in children with growth hormone deficiency. Lancet 1985;i:1069-71. \\ 5 Hughes IA. Steroids and growth. Br Med J 1987;295:683-4. \\ 6 Preece MA. The effect of administered corticosteroids on the growth of children. Postgrad Med J 1976;52:625-30.}

Correspondence to Dr J K H Wales, Department of Paediatrics, University of Sheffield, Children's Hospital, Western Bank, Sheffield S10 2TH.

Accepted 19 April 1988

\title{
Rubella immunisation for girls over 14 years
}

\section{T HODES}

Community and Continuing Care Unit, Islington Health Authority, London

SUMMARY Rubella vaccination was offered to a cohort of schoolgirls 14 years and over whose immune state was unknown. This increased the percentage vaccinated or known to be immune from $86 \%$ to $90 \%$. It is recommended that rubella vaccination should be offered to girls until they leave school at 16 years of age.
The uptake of rubella vaccine by schoolgirls has increased since 1976 but in most areas is still below $90 \% .^{1}$ In inner city areas absenteeism, failure to return consent forms, intercurrent illness, parental refusal, and desire to attend their own general practitioner, have a negative influence on vaccine uptake. ${ }^{2}$ High mobility of the population and administrative difficulties within schools are additional factors.

The schoolgirl rubella vaccination programme is 
offered to all girls between 11 and 13 years. It is then discontinued as girls aged 14 years and over must have preliminary screening for rubella antibody because of the risk of pregnancy. ${ }^{3}$ The school health service has contact with girls until the age of 16 , leaving two further years during which vaccination could be offered. This study describes a programme for schoolgirls, 14 years and over, to determine their immune state and subsequent acceptance of vaccination.

\section{Subjects and methods}

The subjects were girls in their third year at secondary school, 14 years old and over, who had not been vaccinated by June 1985 , and who were attending the five local authority girls secondary schools in the Inner London Borough of Islington. Permission was obtained from each head teacher.

Details of rubella vaccination are normally entered in the school medical records (form $10 \mathrm{M}$ ) and school nurses keep a list of girls who do not attend. Using this information, the nurses identified the girls with unknown immune state and told them about the scheme. Parents gave written consent for serotesting and vaccination. An explanatory letter urging them to accept the programme was enclosed.

The school nurse arranged the session with clerical help and one clinical medical officer who took all the blood samples. Sessions or individual appointments were arranged depending on the number of girls. A thumb prick was made with an autolet and $0.5 \mathrm{ml}$ of blood was collected into a plastic container. A venepuncture was offered but rarely chosen. The specimens were tested for rubella antibody by radial haemolysis at the local district general hospital and those with zone diameters corresponding to more than $15 \mathrm{IU} / \mathrm{ml}$ were considered immune.

Each girl was given a card with her rubella status and the parents were informed by letter. The school nurse arranged a time for the clinical medical officer to vaccinate those who were non-immune.

\section{Results}

In June 1985,503 of 586 third year girls $(86 \%)$ had a clear record of having been vaccinated between 11 and 13 years of age, the uptake varying from $72-100 \%$ between the five schools (table). Of the 83 girls who were still in school and whose immune state was unknown, $56(67 \%)$ were offered the programme. Out of these 56 girls, $25(45 \%)$ accepted. All but four were seropositive and these four girls were vaccinated. Thus by the end of the programme $528(90 \%)$ of third year girls had either been vaccinated or were known to be seropositive.

\section{Discussion}

It is a matter of urgency to increase rubella vaccination uptake in schoolgirls. Introduction of the triple measles, mumps, and rubella vaccine will still require further selective vaccination unless childhood uptake levels are raised rapidly. ${ }^{4}$

The different uptakes between the schools largely reflect the enthusiasm of the individual school nurses as the school populations are similar. School 5 had already achieved $100 \%$ uptake in those under 14 years of age because, of the nurse's persistent efforts.

The 'sweeping-up' programme was offered to all the 19 eligible girls in school 2 , while in schools 1,3 , and 4 it was offered to $24(59 \%)$, six $(55 \%)$, and seven $(58 \%)$ of those eligible, respectively. The nurse needs to be highly motivated to keep her own records up to date, to search through the school medical records, and look for missing records when the mobility of the population is estimated at $20 \%$. Girls often playing truant makes contact very difficult.

The nurse in school 2 was particularly successful and enthusiastic because of the poor uptake between 11 and 13 years $(72 \%)$. In her school a higher proportion of eligible girls participated in this programme than in schools 1,3 , and 4 . Nonparticipants included truanters, refusers, and failures

Table Outcome of rubella vaccination programme in girls, 14 years and over, attending the five schools studied

\begin{tabular}{|c|c|c|c|c|c|c|}
\hline & \multicolumn{6}{|l|}{ Schools } \\
\hline & $I$ & 2 & 3 & 4 & 5 & Total \\
\hline Total No of girls on roll & 253 & 69 & 88 & 93 & 83 & 586 \\
\hline No who wcre vaccinated at $11-13$ ycars $(\%)$ & $212(84)$ & $50(72)$ & $77(88)$ & $81(87)$ & $83(100)$ & $503(86)$ \\
\hline No with unknown immune status & 41 & 19 & 11 & 12 & 0 & 83 \\
\hline No who werc offered programme & 24 & 19 & 6 & 7 & 0 & 56 \\
\hline No who participated & 10 & 10 & 3 & 2 & 0 & 25 \\
\hline Total vaccinated or known immunc after programme( $\%)$ & $222(88)$ & 6) (87) & $80(91)$ & $83(89)$ & $83(100)$ & $528(90)$ \\
\hline
\end{tabular}


to return consent forms. Consent was asked for both serotesting and vaccination, although some parents may have preferred to decide about vaccination once the immune state was known. Starting this programme earlier in the term may have given more time for follow up, including personal contact by phone or home visits.

All those who wanted to participate were able to as the clinical medical officer went to the school on an individual basis, rather than for an immunisation session. For example, two girls were vaccinated after they signed the morning register and before they played truant that day. In agreement with others, ${ }^{5}$ the finger prick was found to be acceptable to most schoolgirls and allows easy collection of blood for serotesting.

In girls 14 years and over serological testing is currently recommended because of the risk of unnecessarily vaccinating a pregnant woman. Recent studies have not been able to show an association between congenital rubella syndrome and vaccination during pregnancy or before conception. ${ }^{6}$ Schoolgirls who play truant are likely to miss vaccination and may be at risk from an unplanned teenage pregnancy.

Although only four non-immune girls were identified, all were subsequently vaccinated, and the percentage of those known to have been vaccinated or immune increased from $86 \%$ to $90 \%$. It is better to vaccinate late in secondary school than to rely on girls attending their general practitioner or antenatal clinic. As schoolchildren are accessible by the school health service until they are 16 years old, it must be the responsibility of each community paediatrician to continue the rubella vaccination programme beyond 13 years of age, even though it involves serological testing to fall within the Joint Committee on Vaccination and Immunisation guidelines.

I thank the school nurses, Dr MC Kelsey, microbiology department, Whittington Hospital, London for help and Dr CL Miller and Dr ON Gill, Public Health Laboratory Service Communicable Disease Surveillance Centre, London for their advice.

\section{References \\ ' Department of Health and Social Security Statistics and Research Division. Vaccination and immunisation of children in England 1966-1985. Statistical Bulletin 3/87. Stanmore: DHSS, 1987. (SR2B SBL607.) \\ 2 Sidle N. Rubella in pregnancy: a review of rubella as an infection in pregnancy, its consequences and prevention. London: Sense National Deaf Blind and Rubella Association, 1985. \\ ${ }^{3}$ Department of Health and Social Security. Immunisation against infectious disease. Joint Committee on Vaccination and Immun- isation. London: HMSO, 1984. \\ ${ }^{4}$ Nokes DJ, Anderson RM. Rubella vaccination policy: a note of caution. Lancet 1987;i:1441-2. \\ 5 Zealley H. Rubella screening and immunization of schoolgirls: a long-term evaluation. British Journal of Preventive Social Medicine 1974:28:54-9. \\ 6 Center for Disease Control. Rubella vaccination during preg- nancy-United States, 1971-1985. MMWR 1986;35:276-84.}

Correspondence to Dr D Hodes, Hornscy Rise Health Centre, Hornsey Rise, London N19 3YU.

Accepted 25 Fcbruary 1988

British Paediatric Association

Annual meetings

At York University: 1989 April 11-14

At University of Warwick:

1990 April 3-6

1991 April 16-19

1992 April 7-10

1993 April 20-23 (provisional)

1994 April 12-15 (provisional) 